E3S Web of Conferences 1, 21003 (2013)

DOI: $10.1051 / \mathrm{e} 3$ sconf/20130121003

(c) Owned by the authors, published by EDP Sciences, 2013

\title{
Risk of overestimation of urinary cadmium concentrations: interference from molybdenum
}

\author{
A.I. Cañas, M. Esteban, F. Cutanda and A. Castaño \\ ${ }^{1}$ Environmental Toxicology. Centro Nacional de Sanidad Ambiental. Instituto de Salud Carlos III. Majadahonda, Madrid. \\ Spain. castano@isciii.es
}

\begin{abstract}
We show here that the selection of analytical method is critical when measuring low levels of cadmium in human urine. Cadmium is today usually analyzed by Inductively Coupled Plasma Mass Spectrometry (ICP-MS), which has a higher sensitivity than Atomic Absorption Spectroscopy (AAS). ICP-MS cadmium measurements show interference from tin $\left({ }^{114} \mathrm{Sn}\right)$ and molybdenum oxides, which can result in an overestimation of cadmium levels. The ${ }^{114} \mathrm{Sn}$ interference is stable and can be mathematically corrected. Molybdenum concentrations in urine are variable and different from individual to individual. We have estimated the degree of error which molybdenum interference introduces in the measurement of cadmium in urine by conventional ICP-MS. 268 urine samples from mothers and their children were measured. Removal of the molybdenum oxide interference (DRC-ICP-MS method) reduced urinary cadmium concentrations significantly $(47.8 \%)$. The urinary molybdenum concentration in children was higher than in their mothers, resulting in greater overestimation. Our results clearly show that the DRC method is essential for reliable measurements of urinary cadmium concentrations, particularly in children. Furthermore, care should be taken when comparing Human Biomonitoring data for cadmium in urine and attention should be paid to which analytical method has been used (e.g. AAS and ICP-Ms), and especially if the measurements have been corrected for molybdenum interference.
\end{abstract}

Key words: Cadmium, Molybdenum interferences, ICP-MS, Human Biomonitoring.

\section{Introduction}

The general population is exposed to cadmium via the diet, with cereals, vegetables, potatoes, kidney, liver and shellfish being the main contributors. Additionally, the fact that tobacco plants can accumulate this metal from the soil means that smokers have higher cadmium levels than non-smokers (ATSDR, 1999).

Cadmium targets the liver and kidneys, and has also been associated with lung and bone damage (ATSDR, 1999; Järup and Akesson, 2009). The International Agency for Research on Cancer (IARC) considers cadmium to be a human carcinogen (group I), with cadmium levels in blood and urine indicating recent exposure and body burden, respectively (ATSDR, 1999). Human biomonitoring (HBM) is a highly valuable tool for assessing overall human exposure to chemicals. Substances and biological matrices to be monitored are usually prioritized because of resource constraints. The prioritization is based on criteria like: demonstrated adverse effects on human health by the substance, the availability of analytical techniques with enough sensitivity, the existence of reference values for interpretation of results and the matrices for measurements should be ethically acceptable and technically available. Cadmium meets all these criteria and is included in most HBM programs.

Although atomic absorption spectroscopy (AAS) has historically been used to determine cadmium concentrations, inductively coupled plasma mass spectrometry (ICP-MS) is becoming increasingly popular due to its higher sensitivity. Cadmium is usually determined in ICP-MS from its most abundant isotope $\left({ }^{114} \mathrm{Cd}\right)$, which has polyatomic interferences like as molybdenum oxides $\left({ }^{98} \mathrm{Mo}^{16} \mathrm{O}^{+}, \quad{ }^{96} \mathrm{Mo}^{18 \mathrm{O}^{+}}\right)$and molybdenum hydroxide $\left({ }^{97} \mathrm{Mo}^{16} \mathrm{OH}^{+}\right)$and isobaric overlaps with tin $\left({ }^{114} \mathrm{Sn}\right)$. These interferences can result in an over-estimation of cadmium levels. The interference with tin is can be corrected by using a mathematical equation, whereas this is not possible for molybdenum oxides because they are formed during the measurements, and the molybdenum levels in urine are widely varying. 
Molybdenum is an essential element whose main source is food, with the highest levels being found in plants growing above the ground, including legumes and leafy vegetables (Barceloux, 1999). This metal is a cofactor for enzymes (xanthine oxidase, aldehyde oxidase, and sulfite oxidase) involved in different metabolic processes. Molybdenum is excreted in urine (Sardesai, 1993; Tumlund et al., 1995). The evidence of adverse effects from excess molybdenum exposure is limited and it is generally believed to be of low toxicity (CDC, 2011). Jarret et al. studied the influence of molybdenum interference on urinary cadmium measurements using NHANES data (Jarrett et al., 2008), and their findings were subsequently corrected and republished (CDC, 2011).

Any comparison of cadmium levels from HBM studies in different countries, or even when studying temporal trends within a given population, will therefore lead to incorrect final conclusions if molybdenum interferences are not taken into account. Herein we study this interference in 268 urine samples from adults and children.

\section{Materials and Methods}

An ELAN® DRC-e ICP-MS (PerkinElmer SCIEX, Ontario, Canada), equipped with a Meinhard quartz nebulizer, quartz cyclonic spray chamber, alumina injector, and nickel sampler and skimmer cones, was used for cadmium and molybdenum analysis. Cadmium $\left({ }^{114} \mathrm{Cd}\right)$ was analyzed using the standard ICP-MS method and the Dynamic Cell Reaction (DRC-ICP-MS), which eliminates molybdenum oxide interferences. The DRC parameters were $1.7 \mathrm{~mL} / \mathrm{min}$ oxygen (Air Liquide) flow rate and $0.7 \mathrm{rPq}$. Molybdenum was analyzed using the standard ICP-MS method.

Urine samples $(0.2 \mathrm{~mL})$ were diluted with $1.8 \mathrm{~mL}$ of diluent $(1 \%$ nitric acid $\mathrm{v} / \mathrm{v}$ containing $10 \mu \mathrm{g} / \mathrm{L}$ rhodium internal standard; Merck KgaA, Germany). External calibration ranges were $0.025-10 \mu \mathrm{g} / \mathrm{L}$ for cadmium (cadmium standard, Perkin Elmer, USA) and 0.05-250 $\mu \mathrm{g} / \mathrm{L}$ for molybdenum (molybdenum standard, Scharlab, Spain).

The effect of different molybdenum concentrations on cadmium levels was studied by spiking urine aliquots with cadmium to final concentrations of $0.3,0.6,0.8,2$ and $4 \mu \mathrm{g} / \mathrm{L}$, and molybdenum to $125,250,500$ and 800 $\mu \mathrm{g} / \mathrm{L}$.

To determine the effect of molybdenum at low concentrations $(<100 \mu \mathrm{g} / \mathrm{L})$ for a fixed cadmium level, a urine sample containing $0.25 \mu \mathrm{g} / \mathrm{L}$ of cadmium was spiked with molybdenum to final concentrations of 6,12 , 23, 33, 46, 57, 92 and $100 \mu \mathrm{g} / \mathrm{L}$. These samples were diluted with nitric acid and analyzed using the method standard ICPMS.

Clinchek ${ }^{\circledR}$ urine (Recipe, Germany) was analyzed every ten samples as a quality control check.

A total of 268 urine samples from mother-child pairs were collected in the framework of the
DEMOCOPHES (http://democophes.isciii.es) project in Spain. Sampling was conducted in schools in an urban and a rural area between October 2011 and January 2012. The mothers were aged 26-48 years and the children 6-11 years.

\section{Results and Discussion}

In accordance with the findings of Jarret et al. (Jarrett et al., 2008), a direct relationship was found between urinary molybdenum concentration and the difference between the cadmium levels obtained using the standard and DRC methods, and a linear function was established (Figure 1).

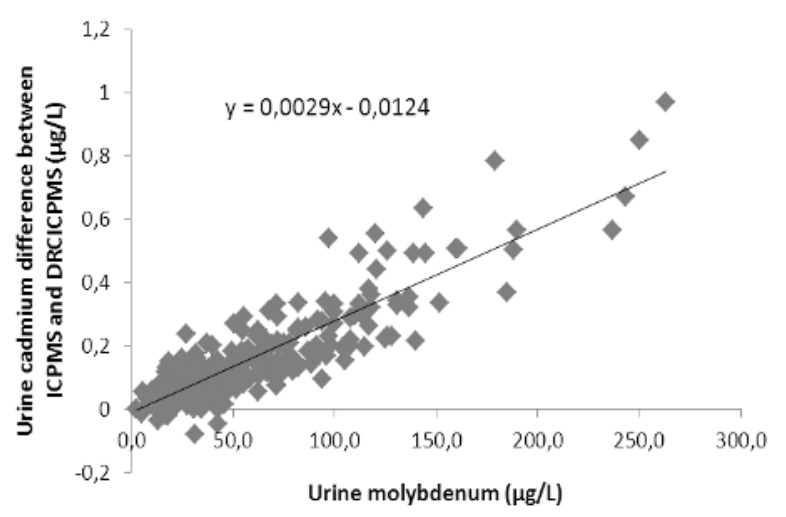

Fig. 1. Observed relationship between urinary molybdenum and the difference between the cadmium levels obtained using the standard ICP-MS and DRC-ICP-MS methods.

The removal of molybdenum oxide interference by DRC-ICP-MS was found to reduce urinary cadmium concentrations by a remarkable amount $(60.5 \%$ at P25, $47.7 \%$ at the geometric mean population, and $25.6 \%$ at P95). The percentage cadmium reduction was high for children samples, where cadmium levels were lower and molybdenum concentrations were higher.

These findings suggest that urinary molybdenum interferes to a greater extent at lower cadmium concentrations. This was confirmed using cadmium concentrations in the range $0.3-4 \mu \mathrm{g} / \mathrm{L}$ (normal in HBM studies) and different molybdenum concentrations (Figure 2). The influence of molybdenum at lower cadmium concentrations was noticeable from $40 \mu \mathrm{g} / \mathrm{L}$ (Figure 3).

This observation is highly relevant for human biomonitoring studies in which cadmium levels are low and molybdenum levels are in the range of influence. The cadmium levels found in the sample population studied here (mother-child pairs) were very low. We should therefore highlight the importance of subtracting molybdenum from ICP-MS, especially when comparing temporal trends from studies in which different methods may have been used (i.e. AAS and ICP MS).

The urinary molybdenum levels found in the study population ranged from 15.9 to $117 \mu \mathrm{g} / \mathrm{L}\left(\mathrm{P}_{10}-\mathrm{P}_{90}\right)$, and 


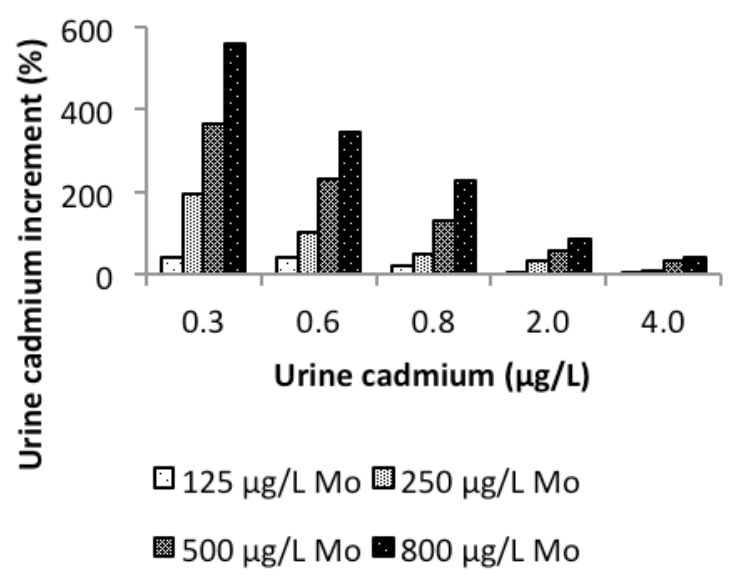

Fig. 2. Increase in cadmium concentration (\%) in urine samples containing different cadmium concentrations in the presence of $125,250,500$ and $800 \mu \mathrm{g} / \mathrm{L}$ molybdenum.

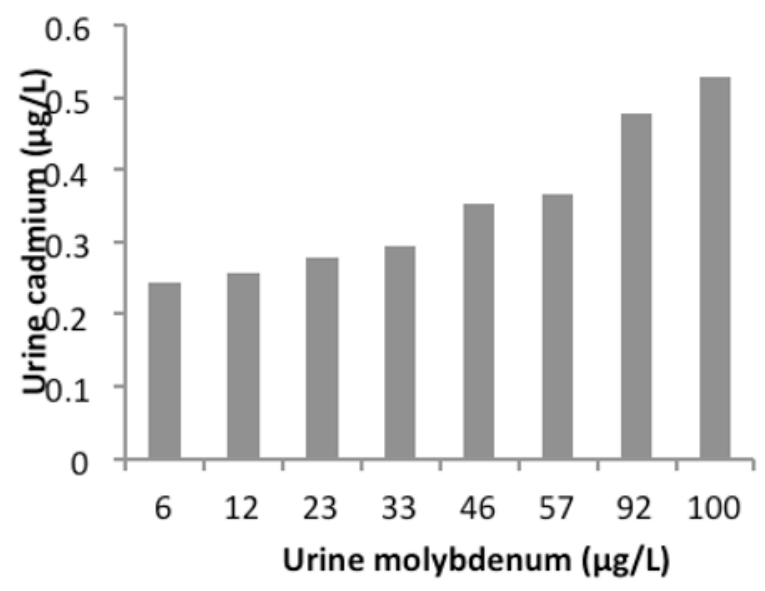

Fig. 3. Cadmium concentrations detected in samples containing a fixed concentration of $0.24 \mu \mathrm{g} / \mathrm{L}$ cadmium and different molybdenum concentrations. Results obtained using standard ICP MS method.

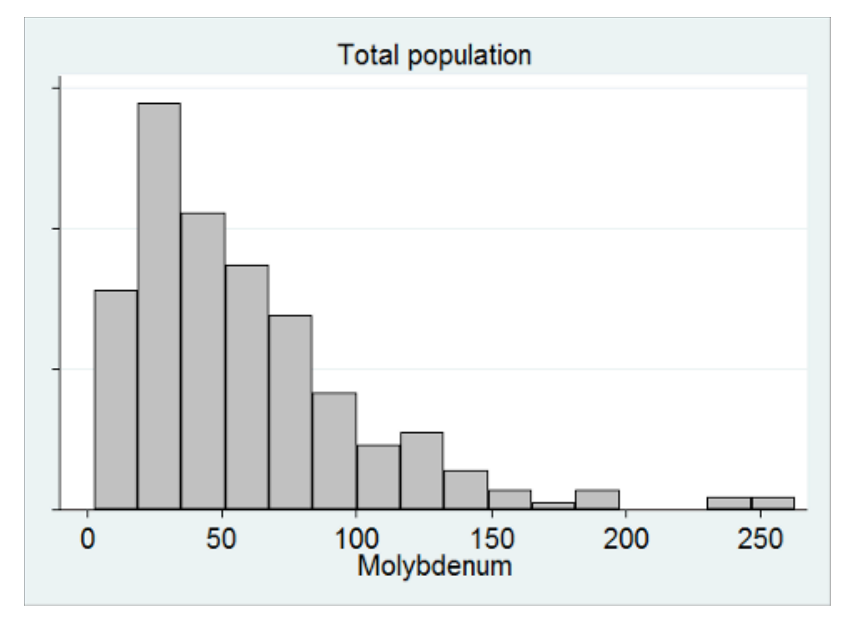

Fig. 4. Histograms of molybdenum concentration for the study population.
Table 1. Cadmium differences $(\mu \mathrm{g} / \mathrm{L})$ and percentage reduction between ICPMS and DRC-ICPMS analysis at geometric mean and 25\% and $95 \%$ percentile in our study population, together with molybdenum concentrations $(\mu \mathrm{g} / \mathrm{L})$.

\begin{tabular}{c|c|c|c}
\hline & $\begin{array}{c}\text { Geometric } \\
\text { Mean }\end{array}$ & $\mathrm{P}_{25}$ & $\mathrm{P}_{95}$ \\
\hline Cd differences between & & & \\
ICPMS and DRC-ICPMS & 0.123 & 0.098 & 0.235 \\
$(\mu \mathrm{g} / \mathrm{L})$ & & & \\
Cd Reduction (\%) & 47.7 & 60.5 & 25.6 \\
Mo $(\mu \mathrm{g} / \mathrm{L})$ & 59.2 & 26.7 & 139.7 \\
\hline
\end{tabular}

the geometric mean was $59.2 \mu \mathrm{g} / \mathrm{L}$ (Figure 4; Table 1). These concentrations were slightly higher than those reported in Europeans (Minoia et al., 2002), Canadians (Health Canada, 2010), and the general US population (CDC, 2011; geometric means: 44, 36.3, and $45.2 \mu \mathrm{g} / \mathrm{L}$ respectively).

Molybdenum values are not always determined in HBM studies unless they are associated with Nutritional or Health Surveys. As such, ICP-MS-derived cadmium levels cannot always be corrected retrospectively as the $\mathrm{CDC}$ does.

\section{Conclusion}

The molybdenum found in urine samples generates significant interferences in cadmium ICP-MS analysis. These interferences are stronger at the low cadmium concentrations found in samples from the normal, non-smoking population, especially in children. Molybdenum should therefore be subtracted from ICP-MS-derived cadmium measurements. Furthermore, care should be taken when comparing cadmium HBM data from different studies if obtained using different analytical methods (e.g. AAS and ICP-Ms), and especially if molybdenum interference has not been corrected, in order to avoid the overestimation of cadmium levels.

\section{Acknowledgements}

Spanish project SEG 1112/10 (MAGRAMA- ISCIII agreement) and DEMOCOPHES (LIFE09 $\mathrm{ENV} / \mathrm{BE} / 000410)$. We would like to thank the volunteers and our DEMOCOPHES partners for their support. www.eu-hbm.info.

\section{References}

ATSDR. Agency for Toxic Substances and Disease Registry. 1999. U.S. Department of Health and Human Services.

Barceloux D.G. Molybdenum. J Toxicol Clin Toxicol 1999b;37:231-7. 
CDC. National Report on Human Exposure to Environmental Chemicals. 2011. National Center for Environmental Health, Atlanta.

Health Canada. Report on Human Biomonitoring of Environmental Chemicals in Canada. 2010.

Heitland P, Köster HD. Biomonitoring of 30 trace elements in urine of children and adults by ICP-MS. Clinica Chimica Acta 2006;365:310-8.

Jarrett JM, Xiao G, Caldwell KL, Henahan D, Shakirova G, Jones RL. Eliminating molybdenum oxide interference in urine cadmium biomonitoring using ICP-DRC-MS. J Anal At Spectrom 2008;23:962-7.

Järup L, Akesson A. Current status of cadmium as an environmental health problem. Toxicol Appl Pharmacol 2009;238:201-8.

Minoia C, Gatti A, Aprea C, Ronchi A, Sciarra G, Turci $\mathrm{R}$, Bettinelli $\mathrm{M}$. Inductively coupled plasma mass spectrometric determination of molybdenum in urine. Rapid Commun Mass Spectrom 2002;16:1313-9.

Sardesai VM. Molybdenum: an essential trace element. Nutr Clin Pract 1993;8:277-81.

Suzuki Y, Endo Y, Ogawa M, Matsuda M, Nakajima Y, Onda N, Iwasaki M, Tsugane S. Determination of Sub-ppb Cadmium in Urine by Solid-Phase Extraction and Inductively Coupled Plasma-Mass Spectrometry. Analytical Sciences 2008;24:1049-52.

Tumlund JR, Keyes WR, Peiffer GL, Ghiang G. Molybdenum absorption, excretion, and retention studied with stable isotopes in young men during depletion and repletion. Am J Clin Nutr 1995;61:1102-9. 